\title{
Surveillance of influenza in Finland during the 2009 pandemic, 10 May 2009 to 8 March 2010
}

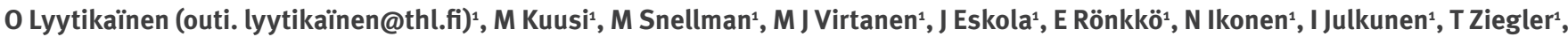
P Ruutu ${ }^{1}$

1. National Institute for Health and Welfare (THL), Helsinki, Finland

Citation style for this article:

Lyytikaïnen O, Kuusi M, Snellman M, Virtanen MJ, Eskola J, Rönkkö E, Ikonen N, Julkunen I, Ziegler T, Ruutu P. Surveillance of influenza in Finland during the 2009 pandemic, 10 May 2009 to 8 March 2010.

Euro Surveill. 2011;16(27):pii=19908. Available online: http://www.eurosurveillance.org/ViewArticle.aspx?Articleld=19908

Article published on 7 July 2011

The first infection caused by pandemic influenza $\mathrm{A}\left(\mathrm{H}_{1} \mathrm{~N}_{1}\right) 2009$ virus was confirmed in Finland on 10 May 2009. The spread of the disease and its impact were monitored using several surveillance systems, such as the national infectious disease register, notifications of clusters of influenza, influenza-like or influenzarelated illnesses, as well as virological, hospital, casebased and mortality surveillance. The epidemic started in early October in the north and then spread to the south about two weeks later. Based on the data from laboratory-confirmed cases, the morbidity was highest in children. The daily number of patients hospitalised with influenza $A\left(\mathrm{H}_{1} \mathrm{~N}_{1}\right)_{2009}$ reached a maximum of over 400 in late November. Of the 1,580 hospitalised patients (median age 32 years), 672 (43\%) had at least one chronic underlying illness, 35 ( $2 \%$ ) were pregnant, $132(8 \%)$ were treated in intensive care units and 74 ( $5 \%)$ required mechanical ventilation. The median age of patients admitted to intensive care units was 48 years and 78 ( $59 \%)$ of them had at least one chronic underlying disease, none were pregnant. Altogether 44 deaths related to influenza $A\left(\mathrm{H}_{1} \mathrm{~N}_{1}\right) 2009$ were recorded (median age 56 years): 40 belonged to high-risk groups on the basis of underlying chronic diseases. Combining data from different surveillance systems gave timely information about the spread of the pandemic and contributed to identifying risk groups.

\section{Introduction}

In April 2009, the first cases of pandemic influenza $A\left(\mathrm{H}_{1} \mathrm{~N}_{1}\right)_{2009}$ were confirmed in Mexico and in California, United States [1]. On June 11, 2009, the World Health Organization declared the first influenza pandemic of the 21 century [2]. In Finland, the first infection caused by the pandemic influenza virus was confirmed on 10 May 2009 [3]. During the early stages of the epidemic until the end of August, all suspected cases were referred to specialist care for virological confirmation and placed in isolation at home or in a hospital depending on the patient's condition. During this period, most of the cases were found among travellers returning from abroad. At the end of July 2009, operational activities related to the containment phase were stopped.
One pandemic vaccine dose per each citizen was purchased by the Finnish government for Finland and the vaccine became first available on 12 October 2009. The vaccination was carried out according to the recommended prioritisation order as soon as the vaccines had arrived in the country $[4,5]$.

Here we report how the national surveillance systems were used and adapted to monitor the spread of pandemic influenza and its impact. Moreover, we describe novel surveillance systems that were set up during the 2009 pandemic in Finland. We also present national surveillance data and compare that to data collected in other countries.

\section{Methods}

\section{Population-based surveillance}

In Finland (population 5.3 million), the national healthcare system is organised into 20 healthcare districts (with catchment populations ranging from 68,000 to 1.4 million), which form five tertiary care districts.

All clinical microbiology laboratories report (generally electronically) all influenza A (culture, antigen, serology, P(R) positive findings to the National Infectious Disease Register (NIDR). With each notification, the following information is transmitted to NIDR: type of specimen and date of collection, patient's date of birth, sex, unique national identity code, and place of treatment. After the first case of pandemic influenza $A\left(\mathrm{H}_{1} \mathrm{~N}_{1}\right)_{2009}$ virus infection in Finland, findings positive for pandemic influenza $A\left(\mathrm{H}_{1} \mathrm{~N}_{1}\right) 2009$ virus were recorded in a specific data collection field. Notifications concerning the same patient were merged into a single case. To avoid delays in notification, the laboratories were requested to report their findings every workday between 8 and 9 am. In addition, the laboratories performing specific PCR-based diagnostics for 2009 pandemic influenza $A\left(\mathrm{H}_{1} \mathrm{~N}_{1}\right)$ virus reported every Monday the total number of specimens processed and the number of positive specimens during the preceding week to a web-based notification system. 
Virological surveillance

A specific PCR test for pandemic influenza $A\left(\mathrm{H}_{1} \mathrm{~N}_{1}\right) 2009$ virus was set up on 30 April 2009, at the National Influenza Center of the National Institute for Health and Welfare (THL) [6]. Participants in a pre-existing sentinel network were asked to continue the surveillance and submit up to five nasopharyngeal samples per week from patients who presented with influenza-like illness (ILI) and/or acute respiratory tract infection (URTI) to THL. The sites of the network are located at garrisons $(n=14)$ and healthcare centres at border guard posts $(n=3)$, municipalities/counties $(n=6)$ and private occupational health services $(n=8)$. Specimens obtained via the sentinel network were tested by PCR for seasonal influenza $A$ and B types, parainfluenza 1, 2 and 3, adenovirus, respiratory syncytial virus and specifically for the pandemic influenza $\mathrm{A}\left(\mathrm{H}_{1} \mathrm{~N}_{1}\right)_{2009}$ virus. In addition, arrangements were made with the laboratories performing specific $P C R$ for 2009 pandemic influenza $A\left(\mathrm{H}_{1} \mathrm{~N}_{1}\right) 2009$ virus to send positive specimens to the National Influenza Center at THL for further confirmation, virus isolation and characterisation (genetic and antigenic characterisation of viruses, oseltamivir resistance).

\section{Case-based surveillance}

The following background information was collected from individual cases of pandemic influenza $A\left(\mathrm{H}_{1} \mathrm{~N}_{1}\right)_{2009}$ to a web-based notification system: unique national identity code, symptoms, travelling history within two weeks before the onset of symptoms such as fever $\geq 38^{\circ} \mathrm{C}$, cough, sore throat, diarrhoea and vomiting, underlying illnesses, pregnancy, hospitalisation, radiologically confirmed pneumonia, treatment in intensive care unit, mechanical ventilation, and death. During the early stages of the pandemic from May to June, notifications were made from all suspected cases, of whom specific PCR-based diagnostics were performed. From the beginning of July 2009, only confirmed pandemic influenza cases and from the beginning of November, only hospitalised and deceased cases were notified to this system.

\section{Cluster identification}

The doctors responsible for communicable disease control at healthcare districts were requested to ensure that local clusters of ILI cases would be identified. Later, when sustained local transmission was going on, the focus of data collection shifted to clusters of severe acute respiratory illness (SARI) and situations where schools or day care centres were closed due to illness in children or shortage of staff. Notifications were made by using the outbreak notification system, which is usually used only for suspected food- and waterborne disease outbreaks. The field in the form for additional data was used to provide information on acute respiratory illness with fever. The notifications were processed as usual in the municipality but sent for information only to the doctor responsible for communicable disease control at the healthcare district in question. When needed, THL provided consultation on diagnostic and infection control measures.

\section{Influenza-like illness outpatients visits}

When not all ILI cases were tested by laboratory diagnostics, ILI surveillance was recommended to be conducted at one to two primary healthcare centres in each healthcare district depending on the catchment population and local resources. The clinical case definitions for ILI accepted by the European commission (28/IV/2008) were available at the THL website. Also the corresponding international primary healthcare (ICPC2) and disease classification (ICD-10) codes could be used for outpatient visit calculations. The number and/or percentage of ILI visits to doctors and/or nurses were recorded. No comprehensive data was transmitted to national level, but ILI surveillance was carried out in all healthcare districts.

\section{Hospital surveillance}

From 19 November to 23 December 2009, THL collected daily the number of patients hospitalised with pandemic influenza $A\left(\mathrm{H}_{1} \mathrm{~N}_{1}\right) 2009$ by a web-based surveillance system. The healthcare districts were asked to report every working day the total number of inpatients at hospital wards and in intensive care units for whom pandemic influenza $A\left(\mathrm{H}_{1} \mathrm{~N}_{1}\right) 2009$ infection was either confirmed or suspected, and separately the number for confirmed cases.

\section{TABLE 1}

Prioritisation order of population groups to be vaccinated against pandemic influenza A(H1N1)2009, Finland, 12 October 2009-21 February 2010

\begin{tabular}{|l|l|l|}
\hline Order & Population group & Mean starting week of vaccinations, (range) \\
\hline 1 & $\begin{array}{l}\text { Social and health care professionals, ambulance personnel, and pharmacists in } \\
\text { customer service }\end{array}$ & $43(42-45) 2009$ \\
\hline 2 & Pregnant women & $44(42-46) 2009$ \\
\hline 3 & People from 6 months to 64 years of age at high risk due to their underlying illness & $45(43-48) 2009$ \\
\hline 4 & Healthy children from 6 to 35 months of age & $46-47(45-49) 2009$ \\
\hline 5 & Healthy children and adolescents from 3 to 24 years of age as well as army conscripts & $47(45-50) 2009$ \\
\hline 6 & $\begin{array}{l}\text { People aged 65 years and above who belong to high risk groups due to an } \\
51(47-4) 2009-10\end{array}$ & $2(48-7) 2009-10$ \\
\hline 7 & Rest of the population & \\
\hline
\end{tabular}


Mortality surveillance

Information on all deaths in Finland was obtained from the Population Information System. These data were linked to the cases of pandemic influenza $\mathrm{A}\left(\mathrm{H}_{1} \mathrm{~N}_{1}\right)_{2009}$ notified to NIDR by using the national identity code. Influenza-related death was defined as a death, which occurred within 30 days after the date when the influenza-positive specimen had been taken. In addition, all-cause and excess mortality were assessed by age

\section{FIGURE 1}

Pandemic influenza A(H1N1)2009 cases per 100,000 population reported to the National Infectious Diseases Register by tertiary care districts, Finland 21 September 2009-3 January $2010(n=7,403)$

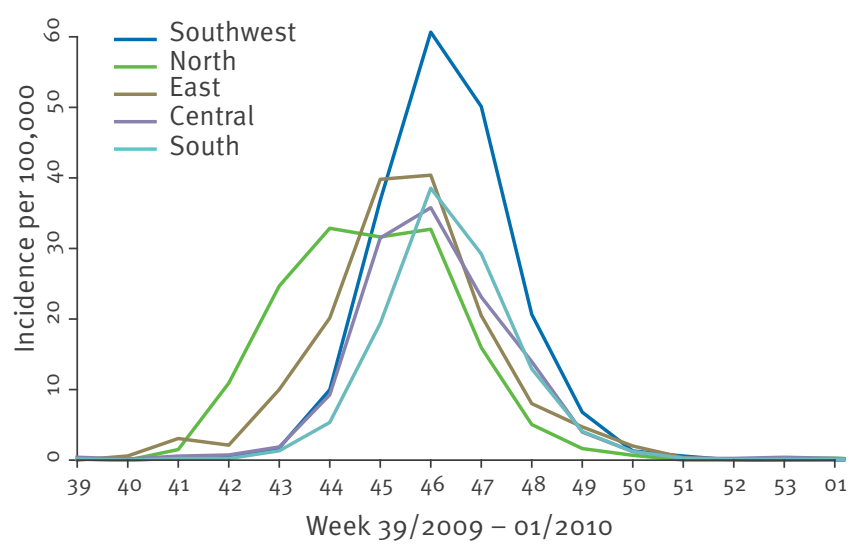

groups and compared to the previous influenza seasons by participating in the European Commission funded European Monitoring of Excess Mortality for Public Health Action (EuroMOMO) project.

\section{Vaccinations}

A total of 5.3 million vaccine doses arrived in Finland between 12 October 2009 and 15 February 2010, first approximately 150,000 doses per week and later more, up to 1.4 million doses per week. The starting weeks of vaccinations of different population groups are shown in Table 1.

Feedback of the surveillance results was given to healthcare districts and health authorities by emails and to the public and media on THL website.

\section{Results}

A total of 7,669 laboratory-confirmed pandemic influenza $A\left(\mathrm{H}_{1} \mathrm{~N}_{1}\right)_{2} 009$ cases were identified in Finland from 10 May 2009 through 8 March 2010.

The first suspected case was reported on 5 May 2009. However, this case was not confirmed by laboratory tests. Between 19 May and 31 August (period prior to sustained domestic transmission including the containment phase), background information was reported for 203 laboratory-confirmed cases; 102 $(50 \%)$ were males, and the median age was 24 years (range: 1-66 years). All healthcare districts reported at

\section{FIGURE 2}

Influenza A and pandemic influenza A(H1N1)2009 cases reported to the National Infectious Diseases Register, and proportion of specimens positive for 2009 pandemic influenza A(H1N1)2009 virus, Finland, 4 May $2009-14$ March 2010

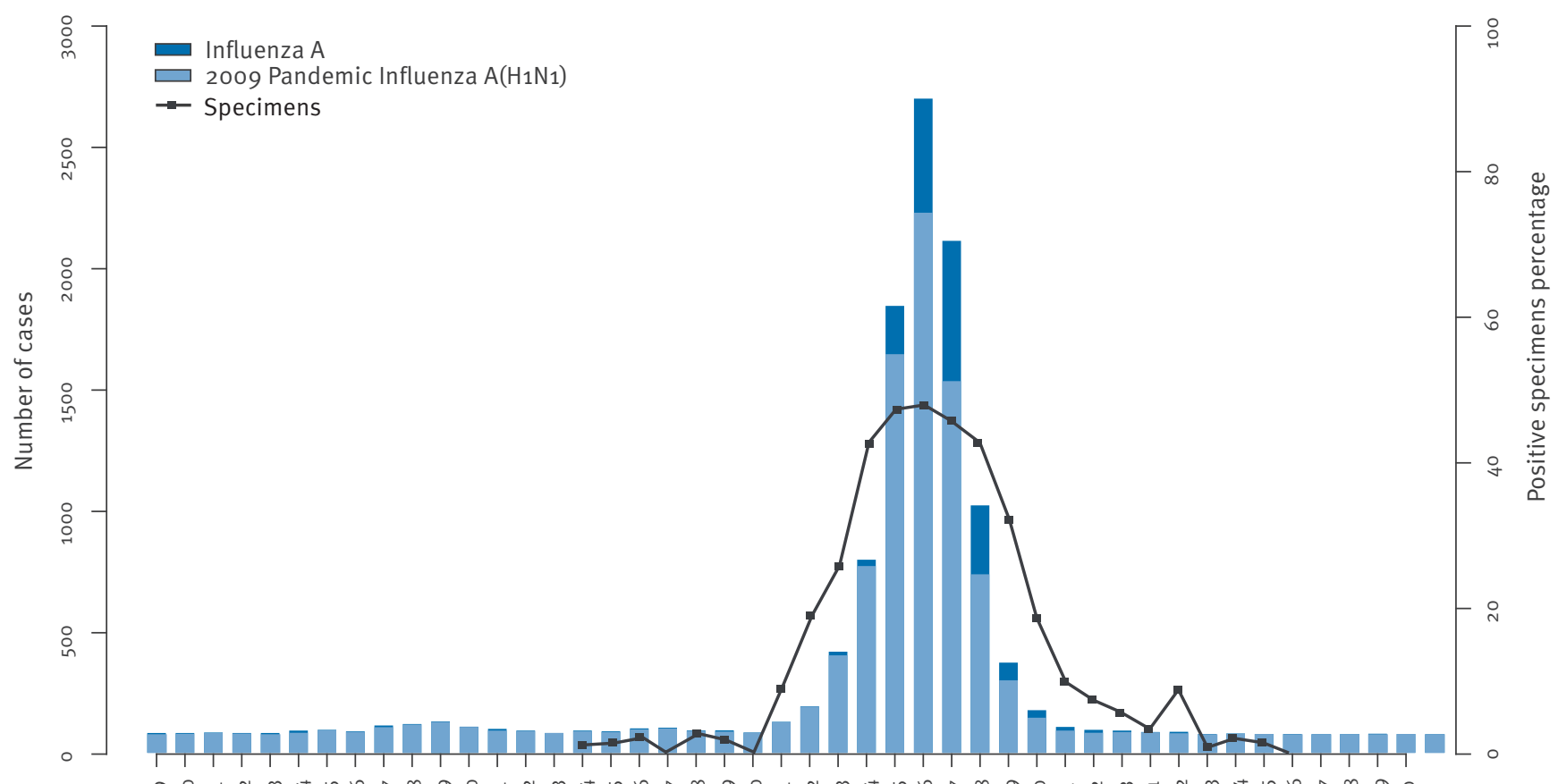

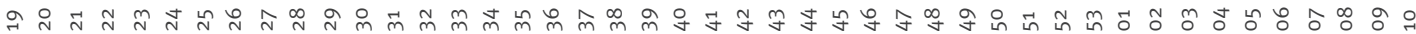

Week 19/2009-10/2010

Influenza A cases ( dark blue bar, $n=1,793$ ) likely included cases caused by pandemic influenza $A\left(H_{1} N_{1}\right) 2009$ virus infection ( $\left.n=7,669\right)$, but they were not confirmed by a subtype-specific PCR test. 
least one laboratory-confirmed case, and almost half of the cases were from the Helsinki-Uusimaa healthcare district. Three of the cases were pregnant women, and $171(84 \%)$ of the patients had no underlying illness. About one third of the reported underlying illnesses $(n=32)$ were mild, such as allergies. Seven cases had diabetes and six chronic pulmonary disease. The most common influenza symptoms were fever $\geq 38^{\circ} \mathrm{C} 167$ (82\%), cough $156(77 \%)$ and sore throat $133(66 \%)$. Of the 150 adult cases, 24 (16\%) presented with diarrhoea and vomiting, while in children ( $\leq 15 y$ years of age) these symptoms were found in nearly one quarter $(13 / 53)$ of cases. Seven cases had radiologically confirmed pneumonia. Out of the 203 laboratory-confirmed cases, 22 $(11 \%)$ were hospitalised and three were admitted to an intensive care unit.

Among the cases with disease onset during May and June 2009 , nearly $90 \%$ had travelled abroad within two weeks before the onset of symptoms. The corresponding figure for the cases reported in August was $60 \%$. Between May and August, the most common travel destinations were the United States $(n=53)$, Asia $(n=49)$, United Kingdom (UK) $(n=22)$, other European countries $(n=40)$, Canada $(n=4)$ and Mexico $(n=4)$. Patients falling ill in August had mainly travelled in Europe.

The number of cases started to increase in Finland between 19 October and 8 November 2009 (weeks 43-45), and peaked first in the north (weeks 43-45) and thereafter, between 2 and 29 November in the south (weeks 45-48) (Figure 1).

A week before the numbers of cases began to rise, the proportion of positive specimens doubled (9.6$19.2 \%$ ) and reached nearly $50 \%$ between 9 and 15 November (Week 46, Figure 2). At the turn of November to December, the proportion of positive specimens decreased, first in the north and thereafter in the south, and from mid-December onwards the pandemic influenza $A\left(\mathrm{H}_{1} \mathrm{~N}_{1}\right)_{2} 2009$ positivity rate of the samples was less than $10 \%$ throughout the whole country. In

\section{FIGURE 3}

Pandemic influenza A(H1N1)2009 cases reported to the National Infectious Diseases Register by age groups,

Finland, 21 September 2009-3 January $2010(n=7,403)$

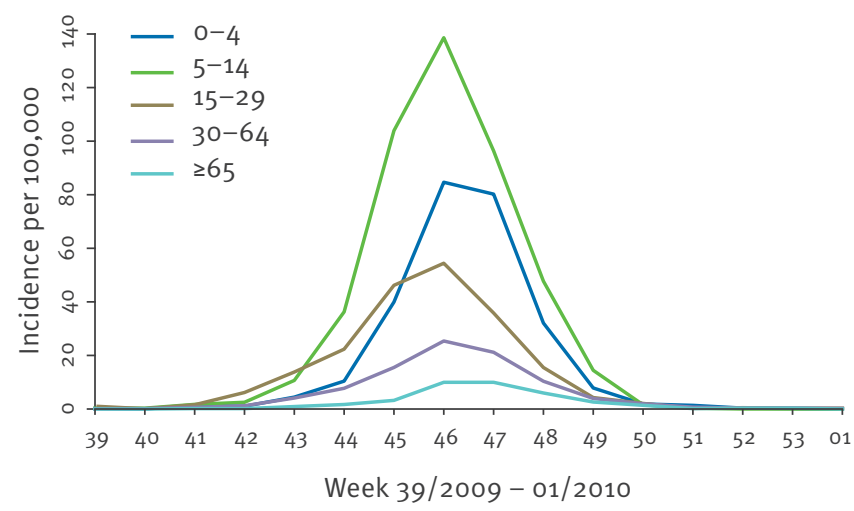

January 2010 there were 20 positive specimens and in February-March only two. As a whole, the proportion of specimens positive for pandemic influenza $A\left(\mathrm{H}_{1} \mathrm{~N}_{1}\right)_{2} 009$ was $33 \%$.

Based on the positive laboratory findings, the morbidity was highest in children (o-14 years) (Figure 3).

The geographical distribution was uneven, and the highest incidence of influenza infection was found in the northern part of Finland (Lapland) (Figure 4).

Based on the hospital surveillance, which started in mid-November (week 47), the burden of influenza patient in hospitals decreased quickly after the epidemic peak occurring at weeks 46-47. During weeks 47-48 there were daily over 400 suspected or confirmed cases in hospitals and daily over 50 patients were treated in intensive care units (approximately 13\% of the intensive care beds in Finland).

In the specimens sent from sentinel sites, garrisons and healthcare centres, the pandemic influenza $A\left(H_{1} N_{1}\right) 2009$ virus was the main virus type detected. In addition, sporadic influenza $\mathrm{A}\left(\mathrm{H}_{3} \mathrm{~N}_{2}\right)$, parainfluenza, adeno and respiratory syncytial (RS) virus were also identified. The hemagglutinin (HA) and neuraminidase (NA) sequences of more than 140 virus isolates were analysed. According to NA sequence, all of them

\section{FIGURE 4}

Influenza A cases reported to the National Infectious Diseases Register per 10,000 population by health care districts, Finland, 5 May 2009-8 March $2010(\mathrm{n}=9,465)$

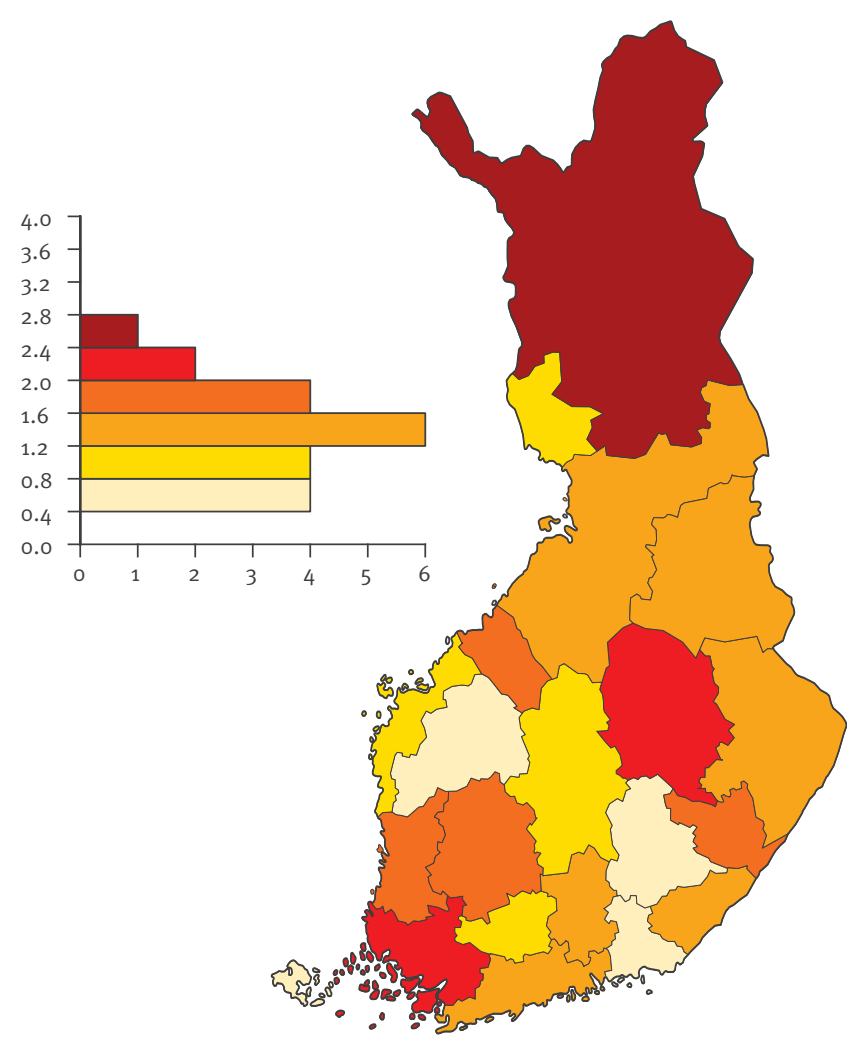


showed a genotype sensitive to oseltamivir. As compared with the influenza A/California/07/2009 prototype virus, the Finnish isolates collected between May 2009 and February 2010 showed maximally 1.4\% and $1.1 \%$ variation in their $\mathrm{HA}$ and NA amino acid sequence, respectively. Some viruses isolated from severe cases had mutations at the residue 222 of the HA protein, but otherwise the viruses from mild and severe infection cases were genetically alike [3].

By the beginning of September 2009, a total of 38 ILI clusters were reported; most of them $(n=33)$ from the Helsinki-Uusimaa healthcare district. Laboratory diagnostics were performed on ILI patient specimens from 13 clusters and in three clusters, several pandemic influenza $A\left(\mathrm{H}_{1} \mathrm{~N}_{1}\right)_{2009}$ infections were confirmed: two clusters were in garrisons [7] and one in a day care centre. At the end of September, at one school in Central Finland, one third of the students and some teachers suffered from ILI; pandemic influenza $A\left(H_{1} N_{1}\right)_{2009}$ was identified in two students. From the end of September to the beginning of October there was an ILI cluster at one school in eastern Finland where around 20 students fell ill; pandemic influenza $A\left(H_{1} N_{1}\right)_{2009}$ infection was confirmed for two students. Almost simultaneously in the same region the number of outpatient visits and telephone calls from the public increased in one healthcare centre where pandemic influenza $A\left(\mathrm{H}_{1} \mathrm{~N}_{1}\right)_{2009}$ was confirmed in three patients. At the end of October ILI clusters were reported from garrisons in northern and north-eastern Finland. At the beginning of November half a dozen ILI clusters were reported from schools in Helsinki metropolitan area, where up to half of the students fell ill and some cases were laboratory confirmed as pandemic influenza. No reports of school or day care closures were received.

Background information was reported for 2,032 of 7,669 cases $(26 \%)$ of which $753(37 \%)$ had at least one chronic underlying illness, 48 (2\%) were pregnant women, 1,580 (78\%) were hospitalised, $132(6 \%)$ were admitted to intensive care (Table 2), and 74 (4\%) required mechanical ventilation. Of the 48 pregnant women, six (13\%) had a chronic pulmonary disease and one ( $2 \%$ ) had diabetes. The underlying conditions included chronic pulmonary disease (310, 15\%), heart disease $(167,8 \%)$, diabetes $(141,7 \%)$, receiving immunosuppressive treatment $(92,5 \%)$ or being immunocompromised $(84,4 \%)$, neurologic disease $(79,4 \%)$, obesity $(37,2 \%)$ and kidney $(26,1 \%)$, liver $(11,0.5 \%)$ or neuromuscular (10, $0.5 \%)$ diseases.

A total of 44 patients infected with pandemic influenza $A\left(\mathrm{H}_{1} \mathrm{~N}_{1}\right) 2009$ died (eight deaths per million), nine of whom were from northern Finland and 15 from the Helsinki metropolitan area, while other cases were scattered throughout the country (median age, 56 years; range 1-88). Of the 44 deceased cases, four were children (range of age, 1-17 years), 26 males and 40 (93\%) belonged to risk groups based on their underlying illnesses, three did not have any underlying illness and for one the information was missing. The preliminary mortality analysis did not reveal excess overall mortality in any age group during the peak pandemic period.

3.7 million vaccine doses were delivered to the regional medical centres and hospital pharmacies. In total, 2.6 million vaccine doses were given [unpublished data THL]. The starting weeks of vaccinations of different population groups are shown in Table 1. Vaccination coverage for the entire country was approximately $50 \%$, but varied considerably in the different age groups: it was highest in children aged 5-14 (76\%) and lowest among young adults aged 20-29 (31\%).

\section{Discussion}

During summer 2009 most of the pandemic influenza $A\left(\mathrm{H}_{1} \mathrm{~N}_{1}\right) 2009$ infections were detected among travellers returning from abroad. Persons who fell ill were mainly previously healthy young adults of whom few developed a severe disease. In early summer, the United States had been the most common travel destination, but later on in the summer infections were also identified among travellers who returned back to Finland from other European countries such as the UK. This is explained by the fact that both New York and London are popular travel destinations. In both cities the first wave of the pandemic influenza $A\left(\mathrm{H}_{1} \mathrm{~N}_{1}\right)_{2009}$ infections started before the closing of the schools for summer holidays $[8,9]$.

In Finland the pandemic started in the north in the beginning of October, followed by spread to the south a couple of weeks later. The epidemic peak in Finland was observed somewhat later than in Norway and Sweden but earlier than in Denmark [9]. The reported ILI clusters at schools and garrisons were often the first sign of the starting epidemic at local level. By December 2009, the number of infections quickly decreased. Like in many other countries, based on the laboratory confirmed cases, the morbidity was highest in children and lowest in the elderly. Following the results of a study by Ikonen et al., the elderly population was considered partly immune: at least 10-20\% of persons aged $65-79$ years, ca. $60 \%$ of those aged $80-89$ years and $95 \%$ of those aged $\geq 90$ years had cross-reacting antibodies that likely originated from infections by the Spanish flu and its descendent viruses in the early 2oth century [10]. Regionally, there were significant differences in morbidity which may be due to differences in the diagnostic activity. This can also be related to the fact that in some population groups and regions the vaccination campaign began too late to control the local epidemic. For example, according to Table 1 and Figure 1, the epidemic peaked in the north during the same week as the first vaccinations occurred in Finland (week 43). The epidemic peaked nationally at week 46 (Figure 2), but the start of vaccinations among the group aged 3 to 24 years occurred one week later (week 47), and the incidence 
among the group of 5 to 14 year olds turned out to be the highest (Figure 3).

During the peak of the pandemic, the daily hospital burden due to suspected or confirmed pandemic influenza $A\left(\mathrm{H}_{1} \mathrm{~N}_{1}\right)_{2009}$ was more than 400 inpatients in the whole country. Like in other countries, hospitalised patients were younger ( $90 \%$ under 65 years of age) when compared to previous influenza seasons $(90 \%$, 65 years of age or older). Approximately half of the patients had at least one underlying chronic illness. The proportion of pregnant women was low ( $2 \%$ vs $5 \%$ in many other countries before vaccination). The most common underlying diseases were chronic pulmonary disease, heart disease and diabetes like in other countries [11-15]. The patients requiring intensive care were older, and more than half of them had some underlying illness. THL received no reports of pregnant women requiring intensive care which, beside the low proportion of pregnant women in general, may be due to the early start and good coverage of the vaccination campaign among pregnant women in Finland.

Altogether, 44 deaths related to pandemic influenza $\mathrm{A}\left(\mathrm{H}_{1} \mathrm{~N}_{1}\right)_{2009}$ infections were confirmed in Finland which, in relation to population size, is more than what was found in other Nordic countries [9]. The linkage of national registers is not internationally commonly available as a tool to assess deaths in relation to specific laboratory-confirmed infections. Thus, the comparisons between countries should be made with caution. The patients who died were older than other hospitalised patients but younger than during previous influenza seasons. Almost all deceased patients had some underlying diseases and thus belonged to the influenza risk groups. One previously healthy child and two other individuals with no underlying diseases died from pandemic influenza $A\left(\mathrm{H}_{1} \mathrm{~N}_{1}\right) 2009$ infection.

When estimating influenza morbidity and mortality, the cases reported to national registries represent only a small proportion of those who were infected with the pandemic influenza $A\left(\mathrm{H}_{1} \mathrm{~N}_{1}\right) 2009$ virus [16]. Atypical clinical pictures, which are common among the elderly and those with underlying diseases are easily missed, as well as mild infections, which recover at home and do not require any medical attention. To obtain a timely picture on the emergence and spread of an influenza epidemic or pandemic, a population-based ILI follow-up system tightly linked with virological surveillance systems should be established in Finland. The final estimates on the effects of the pandemic can be made retrospectively by comparing morbidity and mortality data in the population with previous influenza seasons. Preliminary analyses from the United States and Europe suggest that there was excess mortality among children during the 2009-2010 influenza pandemic compared to previous influenza seasons $[17,18]$.
At present the pandemic influenza $A\left(\mathrm{H}_{1} \mathrm{~N}_{1}\right)_{2009}$ virus has not undergone significant evolution that would hamper the efficacy of the present influenza A/ California/07/2009 $\mathrm{H}_{1} \mathrm{~N}_{1}$ vaccine. It seems that the evolution speed of the influenza $A\left(\mathrm{H}_{1} \mathrm{~N}_{1}\right)_{2009}$ pandemic virus is typical for influenza virus with a yearly rate of $1-1.5 \%$ of amino acid substitutions in $\mathrm{HA}$ and NA proteins. Some of these changes have and will be located at antigenically important sites of the virus requiring constant evaluation of the best possible vaccine candidates for the virus. In addition, no oseltamivir resistant influenza $A\left(\mathrm{H}_{1} \mathrm{~N}_{1}\right) 2009$ virus strains were found in Finland [3]. Thus, epidemiological, virological and population immune status surveillance are important tools in the fight against pandemic and epidemic influenza infections.

\section{Acknowledgments}

We are thankful for the infection teams of the healthcare districts, clinical microbiology laboratories, personnel working at the sentinel site network as well as Sari Jaakola, Juha Makkonen, Teemu Möttönen and Jan-Erik Löflund at THL.

\section{References}

1. Novel Swine-Origin Influenza $A\left(\mathrm{H}_{1} \mathrm{~N}_{1}\right)$ Virus Investigation Team, Dawood FS, Jain S, Finelli L, Shaw MW, Lindstrom S, Garten RJ, et al. Emergence of a novel swine-origin influenza in humans. N Engl J Med. 2009;360(25):2605-15.

2. World Health Organization (WHO). World now at the start of 2009 influenza pandemic. Geneva: WHO; Jun2009. Available from: http://www.who.int/mediacentre/news/ statements/2009/h1n1_pandemic_phase6_20090611/en/ index.html

3. Ikonen N, Haanpää M, Rönkkö E, Lyytikäinen O, Kuusi M, Ruutu $P$, et al. Genetic diversity of the 2009 pandemic influenza $\mathrm{A}\left(\mathrm{H}_{1} \mathrm{~N}_{1}\right)$ viruses in Finland. PLoS One. 2010;5(10):e13329.

4. Ministry of Social Affairs and Health. National preparedness plan for an influenza pandemic. Helsinki: Ministry of Social Affairs and Health; 2007. Available from: http://www.stm.fi/c/ document_library/get_file?folderld=28707\&name=DLFE-3926. pdf

5. National Insitute for Health and Welfare (THL). National Narcolepsy Task Force interim report 31 January 2011. Helsinki: THL; 2011. Available from: http://www.thl.fi/thl-client/pdfs/ dce182fb-651e-48a1-b018-3f774d6d1875

6. Rönkkö E, Ikonen N, Kontio M, Haanpää M, Kallio-Kokko H, Mannonen L, et al. Validation and diagnostic application of NS and HA gene-specific real-time reverse transcriptionPCR assays for detection of 2009 pandemic influenza $A\left(\mathrm{H}_{1} \mathrm{~N}_{1}\right)$ viruses in clinical specimens. J Clin Microbiol. 2011;49(5):2009-11.

7. Aho M, Lyytikäinen 0 , Nyholm JE, Kuitunen T, Rönkkö E, Santanen R, et al. Outbreak of 2009 pandemic influenza $A\left(\mathrm{H}_{1} \mathrm{~N}_{1}\right)$ in a Finnish garrison - a serological survey. Euro Surveill. 2010;15(45):pii=19709. Available from: http://www. eurosurveillance.org/ViewArticle.aspx?Articleld=19709

8. World Health Organization (WHO). Situation updates pandemic $\left(\mathrm{H}_{1} \mathrm{~N}_{1}\right)$ 2009. Geneva: WHO. [Accessed 01 July 2011]. Available from: http://www.who.int/csr/disease/swineflu/ updates/en/index.html/

9. European Centre for Disease Prevention and Control (ECDC). Weekly Influenza Surveillance Overview (WISO). Stockholm: ECDC. [Accessed 01 July 2011]. Available from: http://www. ecdc.europa.eu/en/healthtopics/influenza/epidemiological data/Pages/Weekly_Influenza_Surveillance_Overview.aspx

10. Ikonen N, Strengell M, Kinnunen L, Osterlund P, Pirhonen J, Broman $M$, et al. High frequency of cross-reacting antibodies against 2009 pandemic influenza $A\left(\mathrm{H}_{1} \mathrm{~N}_{1}\right)$ virus among the elderly in Finland. Euro Surveill. 2010;15(5):pii=19478. Available from: http://www.eurosurveillance.org/ViewArticle. aspx?Articleld $=19478$ 
11. Jain S, Kamimoto L, Bramley AM, Schmitz AM, Benoit SR, Louie J, et al. Hospitalized patients with $2009 \mathrm{H}_{1} \mathrm{~N}_{1}$ influenza in the United States, April-June 2009. N Engl J Med. 2009;361(20):1935-44.

12. Louie JK, Acosta M, Jamieson DJ, Honein MA for the California Pandemic ( $\left.\mathrm{H}_{1} \mathrm{~N}_{1}\right)$ Working Group. Severe 2009 H1N1 influenza in pregnant and postpartum women in California. N Engl J Med. 2010;362(1):27-35.

13. The ANZIC Influenza Investigators, Webb SA, Pettilä V, Seppelt I, Bellomo R, Bailey M et al. Critical care services and 2009 $\mathrm{H}_{1} \mathrm{~N}_{1}$ influenza in Australia and New Zealand. N Engl J Med. 2009;361(20):1925-34.

14. Fuhrman C, Bonmarin I, Paty AC, Duport N, Chiron E, Lucas E et al. Severe hospitalized 2009 pandemic influenza $A\left(\mathrm{H}_{1} \mathrm{~N}_{1}\right)$ cases in France, 1 July-15 November 2009. Euro Surveill. 2010;15(2):pii=19463. Available from: http://www. eurosurveillance.org/ViewArticle.aspx?Articleld=19463

15. van 't Klooster TM, Wielders CC, Donker T, Isken L, Meijer A, van den Wijngaard CC, et al. Surveillance of hospitalisations for 2009 pandemic influenza $A\left(\mathrm{H}_{1} \mathrm{~N}_{1}\right)$ in the Netherlands, 5 June-31 December 2009. Euro Surveill. 2010;15(2):pii=19461. Available from: http://www.eurosurveillance.org/ViewArticle. aspx?Articleld $=19461$

16. Reed C, Angulo FJ, Swerdlow DL, Lipsitch M, Meltzer MI, Jernigan $D$, et al. Estimates of the prevalence of pandemic ( $\left.\mathrm{H}_{1} \mathrm{~N}_{1}\right)$ 2009, United States, April-July 2009. Emerg Infect Dis. 2009;15(12):2004-7.

17. Centers for Disease Control and Prevention (CDC). $2009 \mathrm{H}_{1} \mathrm{~N}_{1}$ flu: situation update. Atlanta: CDC. [Accessed 01 July 2011]. Available from: http://www.cdc.gov/h1n1flu/

18. Mazick A, Gergonne B, Wuillaume F, Danis K, Vantarakis A, Uphoff $\mathrm{H}$, et al. Higher all-cause mortality in children during autumn 2009 compared with the three previous years: pooled results from eight European countries. Euro Surveill. 2010;15(5):pii=19480. Available from: http://www. eurosurveillance.org/ViewArticle.aspx?Articleld=19480 